\title{
INJERTO DE TEJIDO CONECTIVO SUBPEDICULADO Y COLGAJO POSICIONADO LATERAL AVANZADO PARA EL TRATAMIENTO DE UNA RECESIÓN GINGIVAL EN UN PACIENTE CON TRATAMIENTO DE ORTODONCIA: REPORTE DE UN CASO
}

\author{
${ }^{1}$ Antonio José Díaz C., ${ }^{2}$ Eduardo Covo M., ${ }^{3}$ María Angélica Fonseca R., ${ }^{3}$ Kelly Johana González M., ${ }^{4}$ Antonio Sagbini F. \\ ${ }^{1}$ Odontólogo U. de Cartagena, Especialista en Periodoncia U. Javeriana, Magíster en Educación \\ U. del Norte, Docente U. de Cartagena, ${ }^{2}$ Odontólogo U. Javeriana, Especialista en Endodoncia \\ U. Javeriana, Docente U. de Cartagena, ${ }^{3}$ Estudiante X semestre F. de Odontología, U. de Cartagena, \\ ${ }^{4}$ Estudiante de la Especialización en Ortodoncia, U. de Cartagena
}

Autor responsable de correspondencia: Antonio José Díaz C.

Dirección de Correo Electrónico: antoniodiazc@yahoo.com

\section{RESUMEN}

Todo movimiento ortodóntico tiene un efecto directo en el periodonto; se ha reportado la presencia de recesiones gingivales en personas con tratamiento ortodóntico por lo que antes de iniciar un movimiento deben evaluarse adecuadamente los tejidos circundantes. Se presenta el caso de una paciente con retracción del margen gingival a nivel del incisivo central inferior izquierdo y ausencia de encía adherida asociada al tratamiento ortodóntico, se describe la técnica quirúrgica utilizando tejido conectivo subepitelial del paladar combinado con un colgajo desplazado lateral, obteniéndose excelentes resultados estéticos y buena cobertura radicular. [Díaz AJ, Covo E, Fonseca MA, González KJ, Sagbini A. Injerto de tejido conectivo subpediculado y colgajo posicionado lateral avanzado para el tratamiento de una recesión gingival en un paciente con tratamiento de ortodoncia: Reporte de un caso. Revista Ustasalud Odontología 2007; 6: 53 - 59]

Palabras clave: Recesión gingival, Movimientos ortodónticos, Injertos de tejido conectivo, Injertos subpediculados, Colgajo posicionado lateral.

\section{SUBPEDICLE CONNECTIVE TISSUE GRAFT AND LATERALLY POSITIONED FLAP ADVANCED FOR THE TREATMENT OF GINGIVAL RECESSION IN A PATIENT WITH ORTHODONTIC TREATMENT: A CASE REPORT}

\begin{abstract}
Fixed appliance orthodontic treatment has been shown to produce deleterious effects on the periodontal complex. Gingival recession is a periodontal alteration commonly found in patients with orthodontic treatment, therefore it is important to recognize and correct areas of actual or potential stress before orthodontic therapy. This clinical report describes the case of a patient with gingival recession in a left mandibular central incisor associated with orthodontic treatment. A radicular covering with a connective graft from palate combined with laterally positioned flap is used in order to solve the case providing excellent esthetic results and root coverage.
\end{abstract}

Key Words: Gingival Recession, Orthodontic tooth movement, Connective tissue graft, Subpediculated grafts.

Recibido para publicación: 4 de diciembre de 2006. Aceptado para publicación: 30 de mayo de 2007.

\section{INTRODUCCIÓN}

La recesión gingival es un trastorno de instalación lenta, progresiva y destructiva en la cual la encía adherida de uno o varios dientes, se encuentra apical a la unión cemento-esmalte, ${ }^{1,2}$ ocasionalmente involucra a la unión mucogingival y a la mucosa alveolar adyacente, ${ }^{3}$ la hipersensibilidad en la superficie radicular expuesta dificulta la remoción mecánica de la placa bacteriana, favorece la formación de cálculo y caries en la zona afectada. ${ }^{2,4}$ Además, cuando se presenta en dientes anteriores produce un aspecto antiestético y temor en algunos individuos a la posible pérdida del diente involucrado. ${ }^{5,6}$

La recesión gingival tiene una etiología multifactorial asociada con factores anatómicos, pa- 
tológicos, mecánicos e iatrogénicos. ${ }^{7,8}$ Entre los factores anatómicos se encuentran: escasa encía adherida, prominencia radicular, dehiscencias óseas, inserción alta de frenillos y malposiciones dentarias en las que la lámina ósea se adelgaza o su altura decrece. Los factores patológicos incluyen la placa bacteriana y el cálculo dental. Entre los factores mecánicos se encuentra el traumatismo por cepillado dental vigoroso. Los factores iatrogénicos incluyen extensiones subgingivales de prótesis fijas, diseño inadecuado de aparatología removible y movimientos ortodónticos. Con respecto a este último factor estudios realizados por Coatoam y colaboradores (1981), Andlin-Sobocki y Bodin (1993), plantean que el movimiento vestibular reduce las dimensiones gingivales vestibulares mientras que se ve un aumento después del movimiento lingual. ${ }^{9,10}$ En sus estudios utilizaron monos e investigaron las alteraciones de los tejidos blandos con movimientos de inclinación, extrusión y lateralidad, en incisivos en los cuales se observó una disminución y migración apical del margen vestibular.

Díaz y colaboradores, en el 2005, establecieron la prevalencia de recesiones gingivales en pacientes con tratamientos ortodónticos atendidos en la clínica del Postgrado de Ortodoncia de la Universidad de Cartagena entre el 2004 y el 2005. Se observó un $54 \%$ de los pacientes con recesiones gingivales, la recesión tipo I se presentó en un mayor porcentaje y el maxilar inferior el más afectado. ${ }^{11}$ Por lo tanto, se debe pensar en una relación de la ortodoncia con la periodoncia e instaurar así un tratamiento integral, para garantizar éxito y bienestar en los pacientes atendidos.

La literatura describe muchas técnicas quirúrgicas mucogingivales para cubrir las superficies radiculares expuestas, tales como: autoinjerto gingival libre, el colgajo de doble papila, el colgajo posicionado lateralmente, El injerto gingival libre con colgajo posicionado coronal multietapico, el injerto de tejido conectivo subpediculado y la utilización de membranas de regeneración ósea guiada. Se tiene en cuenta que se justifica realizar un procedimiento de cobertura de una recesión marginal, cuando ella ocasione problemas estéticos, de sensibilidad o de susceptibilidad a caries radicular, para eliminar inserciones musculares o frenillos que ocasionen tracción del margen gingival, crear o aumentar la banda de encía queratinizada cuando el diente vaya a recibir algún elemento protésico que altere la integridad de la encía y cuando a pesar de tener un adecuado control de placa y haber eliminado los factores etiológicos, la inflamación continúe o se incremente la recesión en presencia de escasa encía adherida. ${ }^{1,8}$

Varios procedimientos han sido catalogados como exitosos y predecibles, ${ }^{12-15}$ pero las técnicas más populares identificadas son las técnicas que incluyen colgajos pediculados con injertos gingivales libres, aunque sus resultados estéticos no son los más destacados. En los años ochenta, el injerto subepitelial de tejido conectivo fue introducido como una alternativa terapéutica mucogingival, aumenta así la predicibilidad para cubrir grandes recesiones gingivales localizadas, además, combina las ventajas del injerto gingival libre y el colgajo pediculado. ${ }^{15}$

El injerto subepitelial de tejido conectivo es un procedimiento diseñado para maximizar el suministro sanguíneo al injerto, está indicado para el cubrimiento de recesiones únicas o múltiples, útil en casos donde hay un inadecuado ancho de encía insertada y recesiones profundas. ${ }^{15-17}$ Presenta algunas ventajas con relación a los injertos gingivales libres ya que el postoperatorio es menos incómodo por el hecho de permitir una cicatrización por primera intención en la región donante y el resultado es más estético debido a una mayor uniformidad en cuanto al color con relación a los tejidos adyacentes al área receptora. ${ }^{18}$

En el colgajo desplazado lateralmente, el área donante es adyacente al área receptora, requisito indispensable para poder efectuarlo, siendo además, el colgajo pediculado por su aporte y vascularización propia, de mayor predecibilidad y de sobrevida quirúrgica; a diferencia de los injertos gingivales libres que son tejidos trasplantados de otra región y por ende, el injerto depende de la nutrición por difusión del área receptora, es decir, del periostio. ${ }^{17}$ El colgajo desplazado lateralmente está indicado en recesiones únicas, con una adecuada anchura de encía queratinizada en el sitio donante. No debe ser usado en áreas con poco vestíbulo, múltiples recesiones adyacentes y cantidad insuficiente de encía queratinizada. Tiene muchas ventajas como son la aplicación de la técnica, no requiere mucho tiempo, produce excelentes resultados estéticos, además el área donante es adyacente al área receptora, lo que evita la necesidad de dos áreas quirúrgicas. Entre las desventajas está que sólo es aplicable para sitios únicos de recesión, puede haber riesgo de crear retracciones o problemas mucogingivales en los dientes donantes y se necesita buena profundidad de vestíbulo en el sitio donante. ${ }^{17,19}$ 
Muchos clínicos han intentado combinar diferentes técnicas quirúrgicas con el fin de incrementar la posibilidad de éxito en el cubrimiento radicular. Nelson, en 1987, utilizó injertos de tejido conectivo combinado con un injerto pediculado doble. ${ }^{20}$ Harris, en 1992 a su vez modificó la técnica de Nelson y usó un injerto pediculado dividido seccionado para cubrir injertos de tejido conectivo. ${ }^{21}$ Wennstrom y Zucchelli, en 1996, combinaron colgajos posicionados coronalmente e injertos de tejido conectivos, terapia conocida también con el nombre de técnica bilaminar. ${ }^{18}$

La mayor prevalencia de recesión gingival en los dientes inferiores está relacionada con las características de la encía queratinizada, la cual es más gruesa en el maxilar que en la mandíbula. Las áreas con deficiente grosor son más susceptibles a la retracción del margen gingival debido a la pequeña cantidad de tejido conectivo disponible en el área, que conlleva a una reacción inflamatoria activada por diferentes procesos que afectan la extensión del tejido y conllevan a la recesión gingival., 22 La recesión gingival de los incisivos inferiores ha sido asociada, principalmente, con una higiene bucal deficiente. $^{8}$

Carvalho, da Silva, Cury, Joly (2006) plantean que la elección clínica de la técnica quirúrgica apropiada para la eliminación de las recesiones gingivales, debe tener en cuenta diferentes aspectos tales como pueden ser el número de recesiones gingivales y si son adyacentes o no, la posibilidad de obtener un tejido donante adecuado del área inmediatamente siguiente, además que es más factible combinar los colgajos avanzados con un injerto de conectivo subpediculado como terapia de elección en las recesiones gingivales. ${ }^{31}$

El presente caso describe el tratamiento con un injerto de tejido conectivo subpediculado en combinación con un colgajo deslizante lateral de un paciente con tratamiento ortodóntico de dos años de evolución, recesión gingival y falta de encía insertada a nivel de órgano dentario ${ }^{31}$.

\section{REPORTE DE CASO}

Paciente de 21 años de edad, de género femenino, sin antecedentes sistémicos de importancia que es atendida en el Postgrado de Ortodoncia de la Facultad de Odontología de la Universidad de Cartagena desde hace aproximadamente dos años.
El diagnóstico ortodóntico inicial fue: clase II esquelética, patrón de crecimiento vertical, relación molar derecha e izquierda clase II, relación canina derecha e izquierda clase II, ausencia de $11,12,41$, diastemas entre 43 y 44, línea media superior desviada a la derecha, inclinación mesial de todos los dientes en la arcada superior, extrusión de 14, 15, 17, 24, 25, 26 y 27 , rotación mesiovestibular de 23 , inclinación lingual de $36,37,46$ y 47, extrusión de incisivos anteroinferiores, rotación mesiolingual de 35 , sobreinserción del frenillo labial superior, mordida abierta anterior, empuje lingual, tercio anteroinferior aumentado y perfil convexo.

La paciente fue tratada con la técnica Arco de Canto, y se inició la terapéutica con alambre nitinol 0.16 superior e inferior. Actualmente, es tratada con acero 0.14 superior y acero $0.16 \mathrm{x}$ 0.22 inferior. La biomecánica es elástica intermaxilar clase II 3/16 mediano, se realizó expansión de arco de acero rectangular $0.16 \times 0.22$ para corregir la mordida telescópica.

$\mathrm{Al}$ inicio del tratamiento ortodóntico se evidenció una recesión gingival de $1 \mathrm{~mm}$ a nivel vestibular y mesial del órgano dentario 31. Luego de dos años de tratamiento se observó, en el examen estomatológico, incremento en la recesión gingival y falta de encía insertada a nivel del mismo órgano dentario, con una profundidad al sondaje normal; se realizaron mediciones con una sonda periodontal milimetrada Hu Friedy ${ }^{\circledR}$ la cual reveló una retracción del margen gingival de $9 \mathrm{~mm}$ a nivel vestibular y $4 \mathrm{~mm}$ a nivel mesial a partir de la línea amelocementaria del órgano dentario 31 (Figura 1). La recesión gingival se extendía apical a la unión mucogingival y se evidenció pérdida de altura del periodonto proximal, la clasificación de la recesión gingival fue consistente con clase III de acuerdo con la clasificación de Miller. ${ }^{3}$ Anterior a la intervención quirúrgica se realizó un raspado y alisado del órgano dentario para detoxificar la superficie radicular expuesta (Figuras 2 y 3 ).

\section{Técnica quirúrgica}

Se anestesió el sitio con Lidocaína ${ }^{\circledR}$ al $2 \%$ con la técnica infiltrativa. La preparación del lecho se inició con una incisión que eliminó el margen gingival en torno a la raíz expuesta (Figura 4) y dos incisiones verticales relajantes, biseladas y paralelas entre sí, por mesial del órgano dentario 31 en la región del área edéntula y a nivel distal del mismo órgano atravesando el espacio interproximal, incluida parte de la papila interdentaria. Las incisiones se iniciaron en el surco gingival con una hoja de bisturí $\mathrm{N}^{\circ} 15$ de Bard 
Parker ${ }^{\circledR}$ paralela a la superficie del diente, contornea la cara vestibular y se extiende hasta el fondo del vestíbulo. Luego se procedió a realizar la disección del colgajo al dejar una capa delgada de tejido conjuntivo y periostio que recubre el hueso (Figura 5).

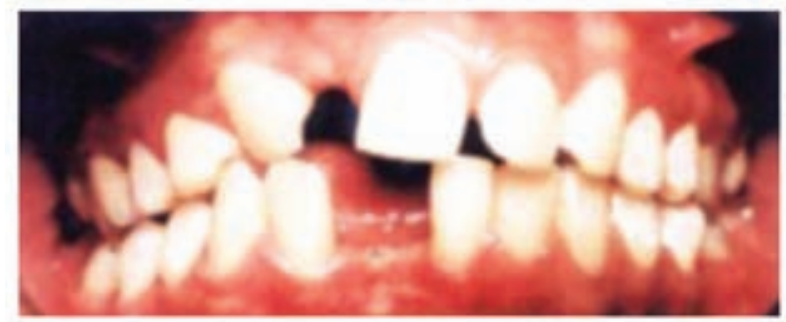

Figura 1. Fotografia inicial de la paciente antes del tratamiento ortodóntico. Obsérvese la recesión marginal incipiente a nivel de órgano dentario del 31.

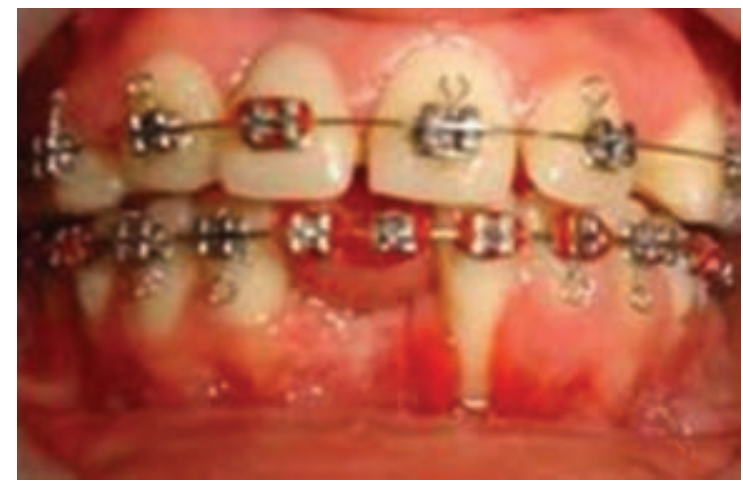

Figura 2. Preoperatorio. Obsérvese la recesión y la falta de encía insertada a nivel del órgano dentario del 31; la encía está enrojecida con márgenes enrollados, se evidencia acumulo de placa bacteriana y depresión del reborde residual en la zona edéntula del diente vecino.

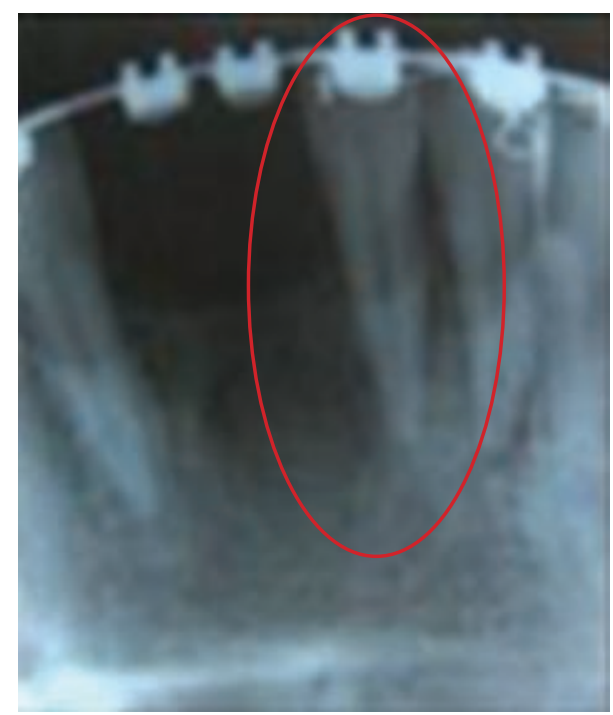

Figura 3. Radiografía periapical de órgano dentario 31 donde se observa ensanchamiento del espacio del ligamento periodontal y pérdida ósea horizontal de $4 \mathrm{~mm}$ a nivel de la cresta ósea alveolar mesial y 2 $\mathrm{mm}$ a nivel de la cresta ósea alveolar distal.

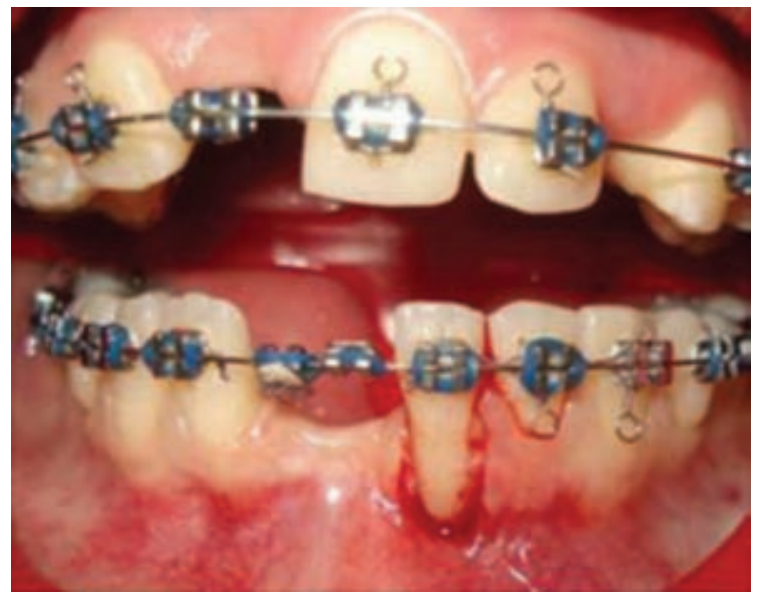

Figura 4. Eliminación de la encía marginal del incisivo central como paso previo de la cirugía mucogingival donde se elimina el epitelio adyacente a la zona que se va a operar.

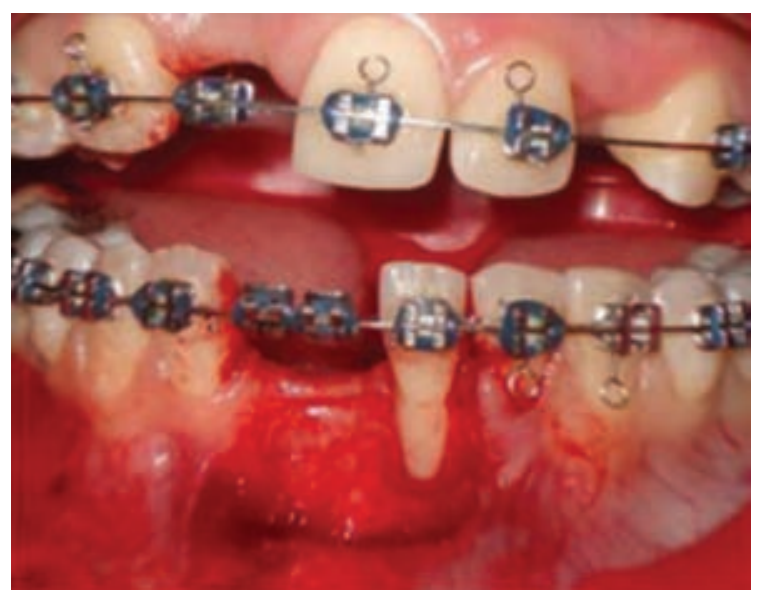

Figura 5. Preparación del lecho receptor, elevación de un colgajo de espesor parcial a nivel del área edéntula vecina al diente que se va a operar.

Posteriormente, se realizó una incisión horizontal en el paladar con la misma hoja $\mathrm{N}^{\circ} 15$ a una distancia de 5 milímetros del margen gingival en la región de premolares del cuadrante derecho (Figura 6). Se colocó la hoja del bisturí perpendicular a la superficie ósea y la incisión se profundizó hasta contactar hueso; se realizó una segunda incisión en la misma área pero esta vez se colocó la lámina paralela a la superficie ósea. Luego se trazaron dos incisiones relajantes internas, solamente, en el tejido conjuntivo, a partir de la primera incisión en dirección a la base del colgajo y se unen estas incisiones con otra horizontal en la base del colgajo. Con ayuda de un periostótomo se levantó y se removió una cuña interna de tejido conjuntivo (Figura 7). El área donante es suturada con puntos simples con seda negra 4-0 a fin de cerrar la incisión horizontal. 


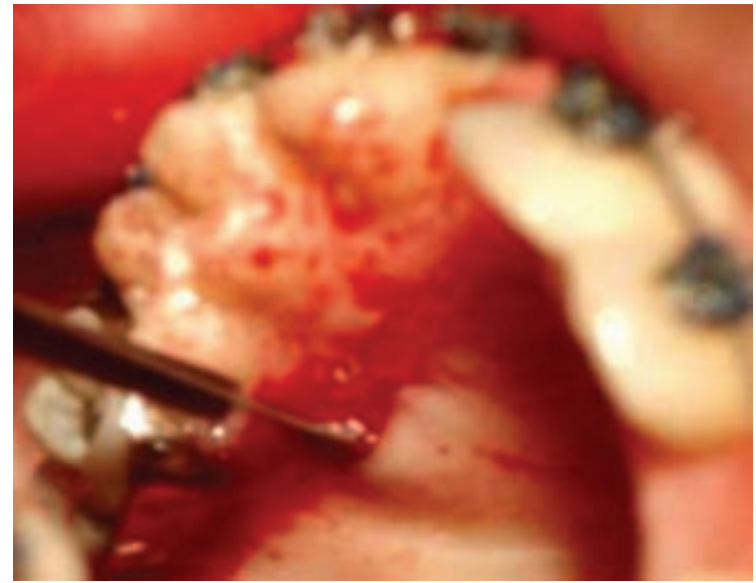

Figura 6. Paladar del que se retira tejido conectivo.

Se colocó el tejido conectivo sobre la raíz descubierta y se procedió a deslizar lateralmente el colgajo en dirección al lecho para cubrir el injerto. Después de colocarlo en la posición deseada se suturó el colgajo mediante puntos simples usando seda negra 4-0 en aguja de 3/8 de círculo con reverso cortante (Figura 8).

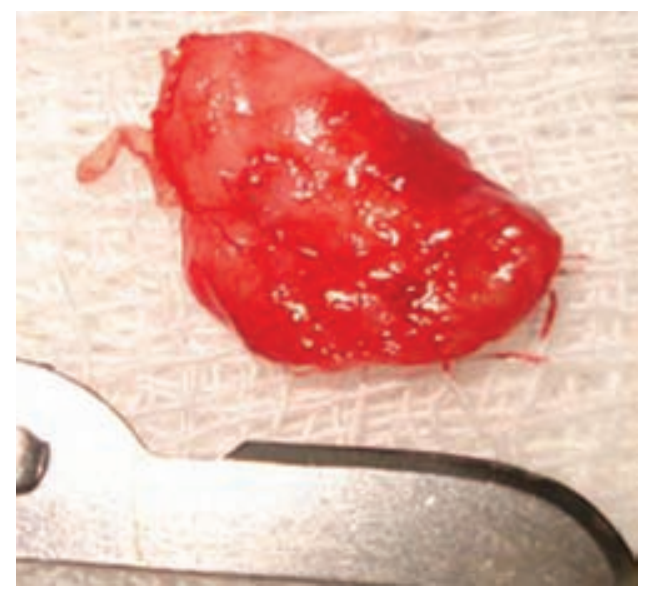

Figura 7. Tejido conectivo para el injerto.

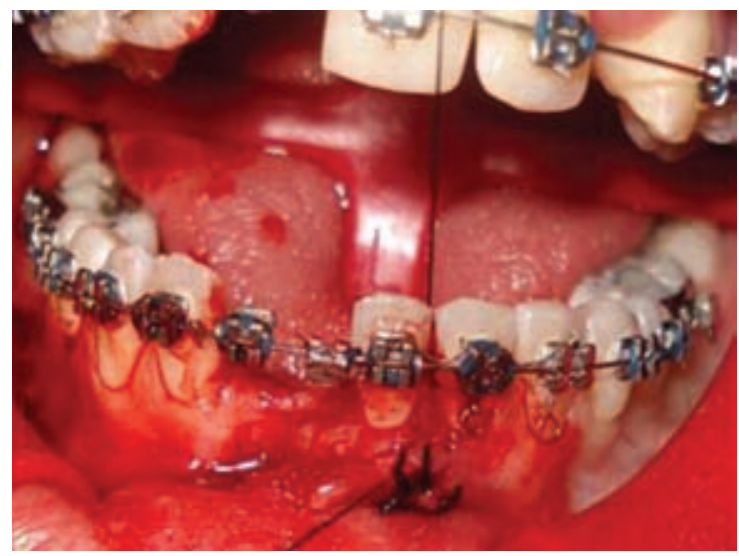

Figura 8. Injerto transferido y cubierto con un colgajo deslizante desplazado en sentido lateral y suturado.
Se limpió el área con suero fisiológico, se colocó clorhexidina en gel y se prescribieron los siguientes medicamentos:

- Amoxicilina, cápsulas de $500 \mathrm{mg}$ \# 21. Tomar una cápsula cada 8 horas por siete días.

- Nimesulide, tabletas de $100 \mathrm{mg} \#$ 10. Tomar una tableta cada 12 horas por cinco días.

- Clorhexidina Enjuague al 0,12\%. Hacer enjuagatorios dos veces al día durante 60 segundos con $10 \mathrm{ml}$ de solución por siete días.

A los siete días se retiraron las suturas del paladar y del área del injerto. Un mes después de la cirugía el ancho de la encía insertada fue de $8 \mathrm{~mm}$, se observó una recesión gingival de $1 \mathrm{~mm}$ a nivel mesial y $0.5 \mathrm{~mm}$ a nivel vestibular de órgano dentario 31 (Figura 9), con óptimos resultados estéticos (Figura 10). Al año de evaluación es factible ver la calidad de los tejidos formados y la altura de la cobertura radicular alcanzada (Figura 11).

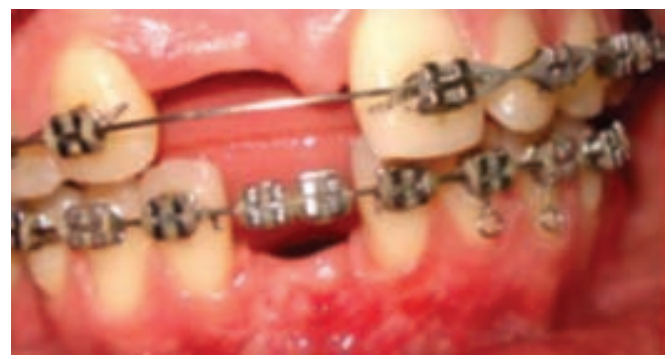

Figura 9. Un mes después de la cirugía.

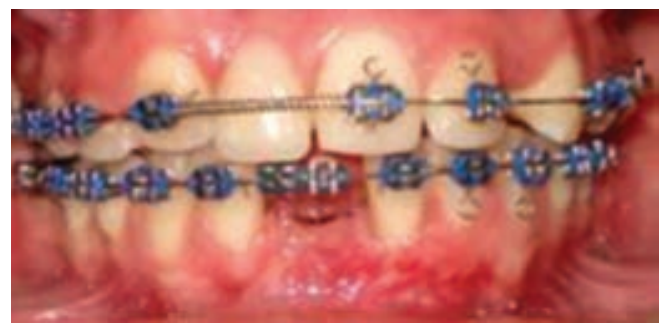

Figura 10. Cuatro meses después de la cirugía. Obsérvese el espesor de tejido en la zona cubierta y el color excelente.

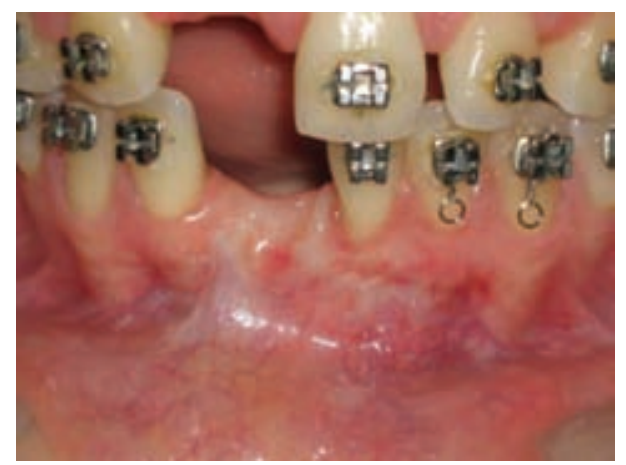

Figura 11. Aspecto de la zona operada un año después. 


\section{DISCUSIÓN}

Todo tratamiento de ortodoncia tiene un efecto directo en el periodonto, los tejidos periodontales pueden estar afectados antes del tratamiento u ocurrir manifestaciones patológicas debidas al tratamiento mecánico, tales como alteraciones en las dimensiones mucogingivales. La evaluación periodontal es un requisito importante antes, durante y después de la terapia ortodóntica.

Díaz y colaboradores (2005), plantean que si la recesión gingival es una alteración periodontal comúnmente encontrada en pacientes con tratamiento ortodóntico, se debe pensar en una relación directa de la ortodoncia con la periodoncia, se instaura así un tratamiento periodontal que se aplique de manera conjunta con el ortodóntico, y garantice un éxito total y un bienestar real en los pacientes atendidos. ${ }^{11}$

En el presente caso la paciente presentaba retracción del margen gingival anterior al tratamiento, el cual se incrementó durante la terapéutica; esto coincide con estudios realizados por Coatoam y colaboradores, en 1981, y por AndlinSobocki y Brodin (1993), quienes plantearon que el movimiento vestibular reduce las dimensiones gingivales vestibulares mientras que se ve un aumento en el ancho de la encía después del movimiento lingual. ${ }^{9,10}$ De igual forma, autores como Pearson, Maynard y Ochsenben, y Foushee y colaboradores coinciden en que algunos pacientes responden a los movimientos frontales de los incisivos y a los laterales de los dientes posteriores con recesión gingival y pérdida de inserción. ${ }^{23-25}$

Dorfman en 1978, realizó un estudio en el que demostró que el $1.3 \%$ de 1150 pacientes presentaron disminución del ancho de la encía queratinizada con mínimos o moderados movimientos labiales de los incisivos inferiores, mientras el $0.69 \%$ de los pacientes tuvieron un incremento en la encía queratinizada asociada con movimientos ortodónticos linguales de los incisivos inferiores. ${ }^{26}$ Está ampliamente aceptado que 2 $\mathrm{mm}$ de encía queratinizada son suficientes para resistir fuerzas ortodónticas, pero defectos mucogingivales preexistentes pueden ser exacerbados durante los movimientos de ortodoncia, de igual forma es importante el grado de estimulación o magnitud de la fuerza empleada. Por lo tanto, es importante reconocer y corregir áreas con condiciones tisulares desfavorables como insuficiencia de la encía, antes de iniciar la terapéutica ortodóntica. ${ }^{9}$

Una variedad de procedimientos estéticos periodontales han sido desarrollados mostrando buenos resultados en la corrección de recesiones gingivales. La predecibilidad del cubrimiento radicular con injertos pediculados de tejido conectivo es excelente. Langer y Langer $(1985)^{15}$, en un estudio de cuatro años, reportaron un cubrimiento radicular de 2 a $6 \mathrm{~mm}$ en 56 casos. Nelson (1987) reportó un promedio de cubrimiento radicular del $91 \% .{ }^{20}$ Por otra parte, Harris (1992) reportó un recubrimiento del $97.7 \%{ }^{16}$ Raetzke, en $1985,{ }^{23}$ describió una técnica en sobre para obtener cubrimiento radicular con injertos de tejido conectivo y encontró un cubrimiento del $80 \%$ de las superficies radiculares expuestas y Allen (1994), con esta misma técnica, reportó un éxito del $84 \% .{ }^{27}$ Jahnke y colaboradores, en 1993 , compararon los resultados obtenidos al realizar injertos epitelizados libres e injertos de tejido conectivo y encontraron un cubrimiento radicular del $43 \%$ para los epitelizados libres y $80 \%$ para los de tejido conectivo. ${ }^{28}$ En un estudio similar, a cinco años, realizado por Paolantonio y colaboradores, en 1997, encontraron que el injerto de tejido conectivo mostró un $85 \%$ de éxito comparado con un 53\% del injerto epitelizado libre. ${ }^{29}$

De Sanctis y Zucheli (2007) plantean que a pesar de la amplia utilización de los diferentes enfoques quirúrgicos mucogingivales, es aun poco predecible la calidad de los resultados, en especial cuando se refiere a la cobertura radicular. Por ello mencionan que independientemente de la técnica a utilizar, es preferible realizar una modificación de la nueva papila, para que se obtengan satisfactorios resultados clínicos en las técnicas quirúrgicas para la cobertura de recesiones aisladas en nuestros pacientes. ${ }^{30}$

Los colgajos desplazados lateralmente han sido evaluados por muchos investigadores (McFall 1967, Smukler 1976, Guinard y Caffesse 1978), el porcentaje de cubrimiento radicular ha sido del 69 al $72 \% .^{17}$

Los injertos de tejido conectivo se pueden usar junto con un colgajo pediculado (el colgajo de doble papila o de reposición lateral). La mayor ventaja de esta técnica es que un colgajo pediculado puede cubrir los injertos de tejido conectivo sobre las superficies radiculares que carecen de irrigación vascular. Además del recubrimiento radicular, la anchura de la encía queratinizada se puede incrementar. Por lo tanto, se puede usar está técnica en las áreas de recesión gingival con encía queratinizada estrecha.

En el presente caso, la combinación de ambas técnicas fue altamente efectiva y predecible para el cubrimiento radicular, incrementa la posibilidad de éxito. 


\section{BIBLIOGRAFÍA}

1. Carranza F, Newman M. Periodontología Clínica. 9na. Ed., McGraw - Hill Interamericana; 2001. p. 903.

2. Marini MG, Greghi SLA, Passanezi E, Santana ACP. Gingival recession: prevalence, extension and severity in adults. J Appl Oral Sci 2004; 12: 250 - 255.

3. Miller PD Jr. A classification of marginal tissue recession. Int J Periodontics Restorative Dent 1985; 5: 8-13.

4. Sotres Vasquez J, García López E, Blanco Ruiz A. Retracción gingival e hiperestesia dentinal: Causas y prevención. Rev Cubana Estomatol. [en línea]. 2004; 41: 0-0. URL disponible en http://scielo.sld.cu/scielo.php?script $=$ sci_arttext $\&$ pid $=$ S0034$75072004000200008 \& I n g=$ es\&nrm $=$ iso

5. Smith R. Gingival recessión. J Clin Periodontol 1997; 24: $201-205$.

6. Allen E, Miller, P. Coronal positioning of existing gingiva: short term results in the treatment of shallow marginal tissue recession. J Periodontol 1989; 60: 316 $-319$.

7. Ericsson I, Lindhe J. Recession in sites with inadequate width of the keratinized gingiva. An experimental study in the dog. J Clin Periodontol 1984; 11: 95 103.

8. Van Palenstein Helderman WH, Lembariti BS, van der Weijden GA, van't Hof MA. Gingival recession and its association with calculus in subjects deprived of prophylactic dental care. J Clin Periodontol 1998; 25: 106 $-111$.

9. Coatoam GW and others. The width of keratinized during orthodontic treatment: its significance and impact on periodontal status. J Periodontol 1981; 52: $307-313$.

10. Andlin-Sobocki, Bodin L. Dimensional alterations of the gingival related to changes of facial/lingual tooth position in permanent anterior teeth of children. A 2-year longitudinal study. J Clin Periodontol 1993; 219 $-224$.

11. Díaz A, Florez JE, Reyes K, Sáenz A, Sepúlveda D, Vargas G, González F. Prevalencia de recesiones gingivales en pacientes con tratamiento ortodóntico atendidos en la clínica del Postgrado de Ortodoncia de la Universidad de Cartagena entre el 2004 - 2005. XVII Encuentro Nacional de Investigación Odontológica ACFO - I Reunión de la International Association for Dental Research (Memorias) Bucaramanga, Colombia 2006. p. 48.

12. Bernimoulin JP, Luscher B, Muhlemann HR. Coronally repositioned periodontal flap. Clinical evaluation after 1 year. J Clin Periodontol 1975; 2: 1 -13.

13. Guinard EA, Caffesse RG. Treatment of localized gingival recessions. Part I. Lateral sliding flap. J Periodontol 1978; 49: 351 - 356.

14. Raetzke PB. Covering localized areas of root exposure employing the "envelope" technique. J Periodontol 1985; 56: 397 - 402.

15. Langer S, Langer L. Subepithelial connective tissue graft technique for root coverage. J Periodontol 1985; 56:715-720.

16. Tozum TF. A promising periodontal procedure for the treatment of adjacent gingival recession defects. J Can Dent Assoc 2003; 69: 155 - 159.
17. Goldstein M, Brayer L, Schwartz Z. A critical evaluation of methods for root coverage. Crit Rev Oral Biol Med 1996; 7: 87 - 98.

18. Wennstrom JL, Zucchelli G. Increased gingival dimensions. A significant factor for successful outcome of root coverage procedures? A 2-year prospective clinical study. J Clin Periodontol 1996; 23: 770 - 777.

19. Grupe J, Warren R. Repair of gingival defects by a sliding flap operation. J Periodontol 1956; 27: 290 -295.

20. Nelson S. The subpedicle connective tissue graft: A bilaminar reconstructive procedure for the coverage of denuded root surfaces. J Periodontol 1987; 58: 95 $-102$.

21. Harris RJ. The connective tissue and partial thickness double pedicle graft: A predictable method of obtaining root coverage. J Periodontol 1992; 63: 477 - 486.

22. Saygun I, Karacay S, Ózdemir A, Sagdiç. Multidisciplinary treatment approach for the localized gingival recession: A case report. Turkish J of Med Sci 2005; 35: $57-63$.

23. Pearson L. Gingival height of lower central incisors orthodontically treated and untreated. Angle Orthod 1968; 38: 337 - 339.

24. Maynard JG, Ochsenben D. Mucogingival problems, prevalence and therapy in children. J Periodontol 1975; 45: 543 - 552

25. Foushee DG, Moriarty JD, Simpson DM. Effects of mandibular orthognathic treatment on mucogingival tissues. J Periodontol 1985; 56: 727 - 733.

26. Dorfman H. Mucogingival changes resulting from mandibular tooth movement. Am J Orthod 1978; 74: $286-297$.

27. Allen AL. Use of the supraperiosteal envelope in soft tissue grafting for root coverage I. Rationale and technique. Int J Periodontics Restorative Dent 1994; 14: $216-227$

28. Jahnke PV, Sandifer JB, Gher ME, Gray JL, Richardson AC. Thick free gingival and connective tissue autografts for root coverage. J Periodontol 1993; 64: $315-322$.

29. Paolantonio M, di Murro C, Cattabríga A, Cattabriga M. Subpedicle connective tissue graft versus free gingival graft in the coverage of exposed root surfaces. A 5-year clínical study. J Clin Periodontol 1997; 24: 51 $-56$.

30. De Sanctis M, Zucchelli G. Coronally advanced flap: a modified surgical approach for isolated recession-type defects: three-year results.J Clin Periodontol. 2007; 34: $262-268$.

31. Cavalho PF, da Silva RC, Cury PR, Joly JC. Modified coronally advanced flap associated with a subepithelial connective tissue graft for the treatment of adjacent multiple gingival recessions. J Periodontol 2006; 77: 1901- 1906 . 